\title{
KAJIAN ETNOBOTANI TUMBUHAN OBAT OLEH ETNIS MASYARAKAT DI DUSUN ARAS NAPAL KIRI DAN DUSUN ARAS NAPAL KANAN DESA BUKIT MAS KECAMATAN BESITANG KABUPATEN LANGKAT
}

\author{
Jamilah Nasution, Putri Dwi Masitah, Riyanto \\ Fakultas Biologi Universitas Medan Area, Sumatera Utara, Indonesia \\ \amilah.nasution83@gmail.com
}

\begin{abstract}
Based on this observation, thre are 42 species of beneficial herbal plant from 27 family grown in Dusun Aras Napal Kiri and Dusun Aras Napal Kanan, Desa Bukit Mas Kabupaten Langkat. The parts of plant usefully are leave (22 species or $47,83 \%$ ), rizomes ( 8 species or 17,39\%), latex (4 species or $8,70 \%$ ), seed (3 species or 6,52\%), stem and root are each (2 species or 4,35\%), and flower (only 1 species or 2,17\%).The Javanese is the Etnis who use the most herbal plants (34 species) whilst Karo and Batakness uses 20 species and 19 species. The wealth of the herb can be used into 4 categories sch as Medecine $(60,47 \%)$, Healthcare(30,23\%), Beautycare (4,65\%), and medicare $(4,65 \%)$.
\end{abstract}

Keywords: Ethnobotany, medicinal plant, Aras Napal

\section{Pendahuluan}

Indonesia sebagai Negara maha ragam hayati memiliki banyak potensi alam dengan iklim tropisnya. Hutan tropis Indonesia memiliki luas terbesar kedua setelah Brazil dan menyimpan banyak sekali kekayaan flora. Dari spesies tanaman yang ada, Indonesia memiliki \pm 35.000 spesies tanaman, dan sampai saat ini baru 4.000 jenis yang diketahui manfaatnya secara langsung oleh masyarakat dan $25 \%$ saja yang telah dibudidayakan, hal ini tentu relative sedikit mengingat keanekaragaman hayati Indonesia yang sangat tinggi dan tak ternilai harganya (Fahreza, 2004).

Pelayanan kesehatan di Indonesia telah berkembang, namun minat masyarakat dalam memanfaatkan pengobatan tradisional tetap tinggi (Mirza, 2008). Prinsip back to nature yang semakin populer membuat masyarakat beralih dari mengkonsumsi obat-obatan kimia ke obat-obatan bahan alami untuk menghindari efek samping yang ditimbulkan oleh obat-obatan berbahan dasar zat kimia sintetis. Selain itu, pengobatan dari bahan alami lebih murah dan bahan bakunya lebih mudah didapatkan. Obat atau ramuan dari bahan alami juga relatif aman dan dapat terhindar dari efek samping yang dapat membahayaan tubuh (A.N.S, 2012).

Pengobatan tradisional memiliki potensi manfaat yang sangat besar dalam pembangunan kesehatan masyarakat. Pemanfaatan bahan alam untuk pengobatan cenderung meningkat. Pada tahun 1999 pemanfaatan bahan alam untuk pengobatan hanya mencapai 20,5 \% dan menurut hasil Survei Sosial Ekonomi Nasional (Susenas) pada tahun 2001 meningkat menjadi 31,7 \% dan $9,8 \%$ Pengobatan tradisional dengan menggunakan bahan-bahan dari tumbuhan juga lebih maju secara internasional. (Kandowangko et al., 2011)

Desa Bukit Mas merupakan salah satu desa yang berada di Kecamatan Besitang, Kabupaten Langkat, Provinsi Sumatera Utara (Thoha, 2009). Desa Bukit Mas yang berbatasan langsung dengan kawasan Taman Nasional Gunung Leuser masih asri dan memiliki keanekaragaman hayati yang cukup tinggi. Masyarakat yang menetap di Desa Bukit Mas pun beragam, khususnya pada Dusun Aras Napal Kiri dan Dusun Aras Napal Kanan. Sebagian masyarakat juga masih memanfaatkan tumbuhan-tumbuhan disekitar tempat tinggalnya untuk dimanfaatkan sebagai obat tradisional. Namun, data tentang etnobotani tumbuhan obat yang digunakan oleh etnis-etnis yang berada di Desa Bukit Mas belum ada. Melihat kondisi ini maka perlu dilakukannya penelitian tentang Kajian Etnobotani Tumbuhan Obat di Desa Bukit Mas Kecamatan Besitang Kabupaten Langkat.

\section{Bahan Dan Metode}

Penelitian ini dilaksanakan di Dusun Aras Napal Kanan dan Dusun Aras Napal Kiri Desa Bukit Mas Kecamatan Besitang Kabupaten Langkat. Metode yang digunakan dalam penelitian ini adalah deskriptif kualitatif dengan teknik wawancara semi terstruktur. Pemilihan responden dilakukan dengan metode purposive sampling yaitu responden dipilih secara sengaja oleh peneliti. Responden yang dipilih berjumlah 5 orang perwakilan dari setiap etnis di Dusun Aras Napal Kanan dan Dusun Aras Napal Kiri.

Pelaksanaan penelitian diawali dengan melakukan observasi lokasi, kemudian pengumpulan data dari hasil wawancar, 
dokumentasi sampel tumbuhan serta analisis data secara deskriptif kualitatif.

\section{Hasil Dan Pembahasan Jenis Tumbuhan Obat dan Bagian tumbuhan yang Dimanfaatkan}

Berdasarkan hasil wawancara dengan masyarakat Etnis Jawa, Karo, dan Batak di Dusun Aras Napal Kiri dan Dusun Aras Napal Kanan Desa
Bukit Mas Kecamatan Besitang Kabupaten Langkat, diperoleh 42 jenis tumbuhan obat dari 27 famili. Ada beberapa famili yang memiliki lebih dari satu jenis tumbuhan obat diantaranya famili Zingiberaceae 8 jenis, famili Piperaceae 3 jenis, famili Lauraceae, Fabaceae, Poaceae, Myrtaceae, Rubiaceae, Euphorbiaceae masing-masing 2 jenis, dan 19 famili lainnya masing-masing diwakili 1 jenis tumbuhan. Data selengkapnya dapat dilihat pada Gambar 1.

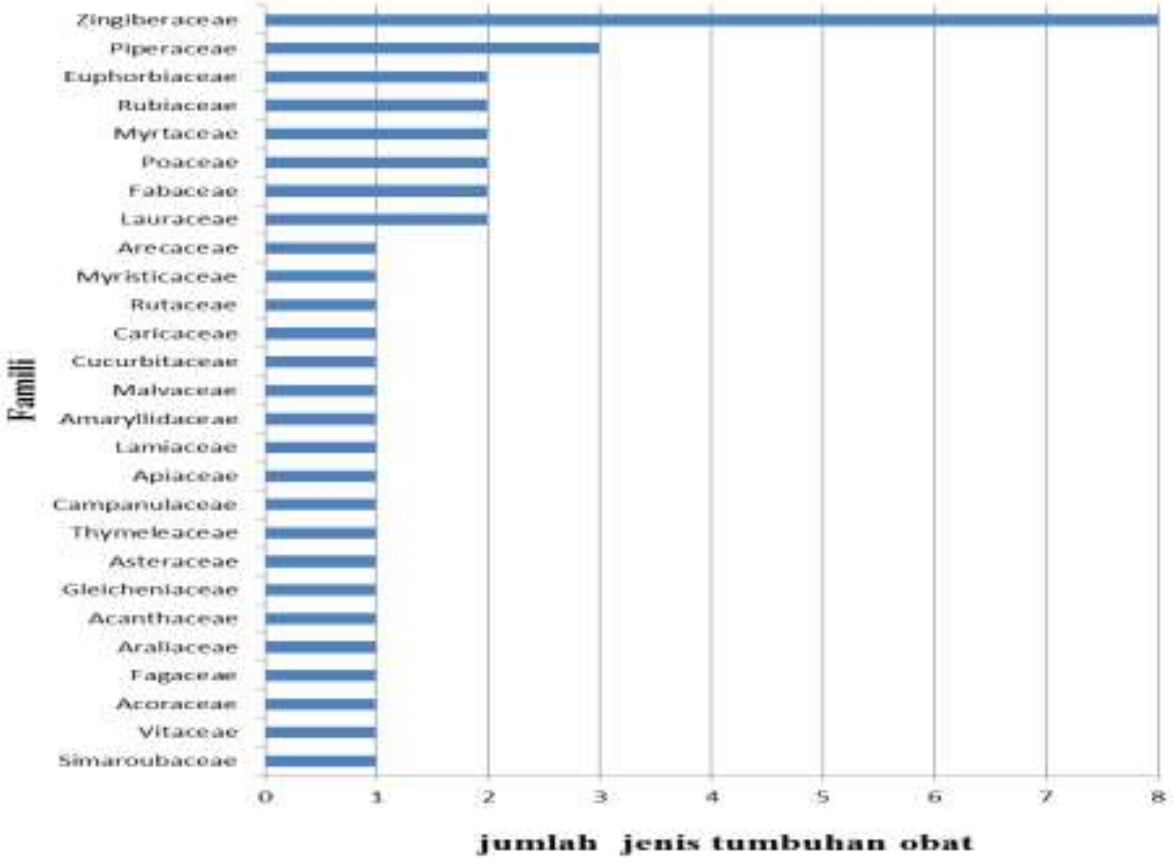

Gambar 1. Jumlah famili tumbuhan obat yang dimanfaatkan oleh masyarakat

Bagian tumbuhan yang dimanfaatkan oleh Etnis Jawa, Karo, dan Batak di Dusun Aras Napal Kiri dan Dusun Aras Napal Kanan Desa Bukit Mas Kecamatan Besitang Kabupaten Langkat adalah

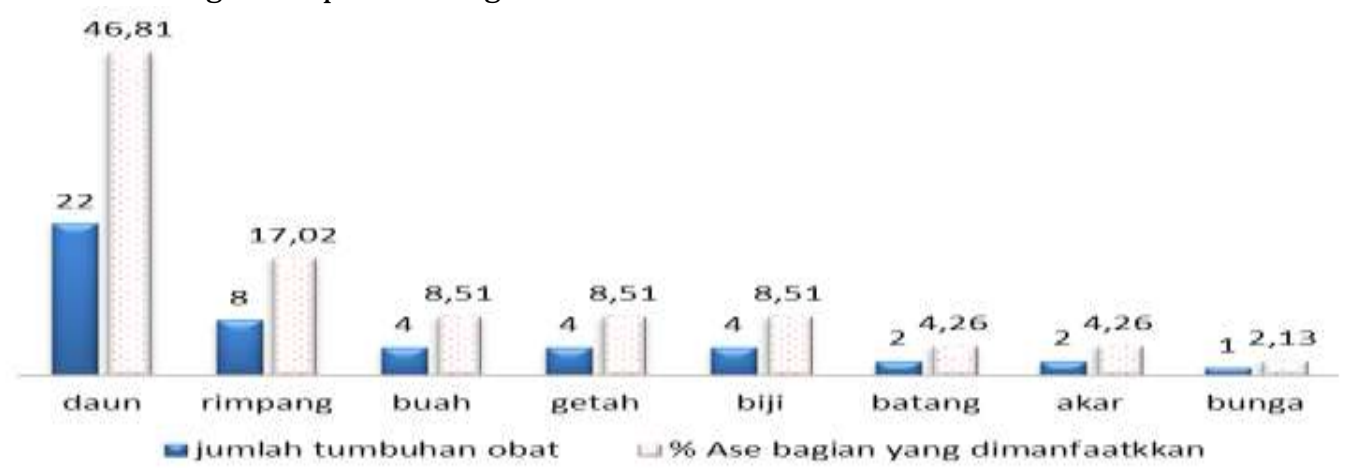

bagian daun, rimpang, buah, getah, biji, batang, akar, dan bunga. Data selengkapnya dapat dilihat pada gambar 2 .

Gambar 2. Bagian tumbuhan yang dimanfaatkan oleh masyarakat sebagai obat.

Gambar 2 diatas menunjukkan bahwa bagian tumbuhan yang paling banyak dimanfaatkan sebagai obat oleh masyarakat adalah bagian daun dengan 22 jenis (46,81\%) yaitu Piper 
burmanii, Paspalum conjugatum, Jatropha curcas, Euphorbia prunifolia, Vitis gracilis, Isotoma longiflora, Centella asiatica, Orthosiphon stamineus, Gossypum Arboreum, Cytrus hystrix, Gleichenia linearis. Tumbuhan yang dimanfaatkan bagian rimpangnya ada 8 jenis tumbuhan $(17,02 \%)$ yaitu Zingiber officinalle, Kaempferia galanga, Acorus calamus, Curcuma langa, Zingiber zerumbet, Alpinia galanga, Boesenbergia pandurata, Zingiber purpureum. Tumbuhan yang dimanfaatkan bagian buahnya ada 4 jenis tumbuhan $(8,61 \%)$ yaitu Morinda citrifolia, Parkia javanica, Uncaria gambiir, Etlingera elatior, Myristica fragrans. Tumbuhan yang dimanfaatkan bagian getahnya ada 4 jenis tumbuhan (8,51\%) yaitu Aquiliria moluccensis, Gleichenia linearis, Jatropha curcas, Etlingera elatior. Bagian biji dimanfaatkan dari 4 jenis tumbuhan $(8,51 \%)$ yaitu Myristica fragrans, Piper albi, Luffa acutangula dan Areca catechu. Bagian batang dari 2 jenis tumbuhan (4,35\%) yaitu Cymbopogon nardus, Etlingera elatior. Bagian akar dari 2 jenis tumbuhan (4,35\%) yaitu Eurycoma longifolia, Spilanthes acmella dan bagian bunga hanya dari 1 jenis tumbuhan $(2,17)$ yaitu Syzygium aromaticum.

\section{Pemanfaatan Tumbuhan Obat}

Berdasarkan hasil wawancara pemanfaatan tumbuhan sebagai obat oleh beberapa etnis di Dusun Aras Napal Kiri dan Dusun Aras Napal Kanan Desa Bukit Mas Kecamatan Besitang Kabupaten Langkatdiperoleh data yaitu Etnis yang paling banyak menggunakan tumbuhan obat adalah Etnis Jawa sebanyak 34 jenis tumbuhan obat. Etnis Karo menggunakan 20 jenis tumbuhan obat dan etnis Batak menggunakan 19 jenis tumbuhan obat.

Etnis Jawa merupakan etnis yang mendominasi di Dusun Aras Napal Kiri dan Dusun Aras Napal Kanan Desa Bukit Mas Kecamatan Besitang Kabupaten Langkat dan ada seorang dukun bayi yang berasal dari Etnis Jawa. Hampir seluruh masyarakat dari berbagai etnis di daerah tersebut datang kepada dukun bayi tersebut untuk mengobati bayi yang sakit atau terkena sawan dan untuk perawatan ibu yang baru melahirkan sehingga Etnis Jawa menjadi etnis yang paling banyak memanfaatkan tumbuhan sebagai obat.

Pada masyarakat Etnis Karo, ada 20 jenis tumbuhan untuk dimanfaatkan sebagai obat. Ciri khas dari penggunaan tumbuhan obat oleh masyarakat Etnis Karo adalah dengan cara dikunyah dan disembur kepada bayi maupun orang dewasa. Masyarakat Etnis karo mendapat informasi penggunaan tumbuhan obat secara turun temurun dan dari para manula, informasi dari masyarakat lain dan tokoh masyarakat karo yang berada di daerah tersebut.

Masyarakat Etnis Batak memanfaatkan 19 jenis tumbuhan obat. Ciri khas dari pemanfaatan tumbuhan obat oleh Etnis Batak adalah dengan menggunakan campuran jeringau, merica, pala, kencur, cengkeh dan jahe yang dihaluskan dan ditapal atau disembur ke tubuh untuk mengobati penyakit demam, batuk, sakit kepala, masuk angin, pegal-pegal dan untuk penghilang rasa capek.

Dari ketiga Etnis tersebut (Jawa, Karo, dan Batak), masyarakatnya saling memberitahukan informasi tentang pemanfaatan tumbuhan obat sehingga informasi tentang pemanfaatan tumbuhan obat di Dusun Aras Napal Kiri dan Dusun Aras Napal Kanan Desa Bukit Mas Kecamatan Besitang Kabupaten Langkat semakin meluas dan banyak tumbuhan yang sama yang digunakan oleh ketiga suku tersebut. Persentase jenis tumbuhan obat berdasarkan etnis yang memanfaatkan dapat dilihat pada gambar 3 .

Dari jenis tumbuhan obat yang dimanfaatkan, 11 jenis $(4,11 \%)$ digunakan oleh semua etnis yaitu Etnis Jawa, Etnis Karo dan Etnis Batak, 5 jenis $(2,74 \%)$ digunakan oleh etnis Jawa dan Karo, 2 jenis (2,74\%) digunakan oleh etnis Karo dan Batak, dan 2 jenis (2,74\%) digunakan oleh etnis Jawa dan Batak, 22 jenis (1,37\%) hanya digunakan oleh 1 etnis dengan 16 jenis digunakan oleh etnis Jawa, 4 jenis digunakan oleh etnis Batak, dan 2 jenis digunakan oleh etnis Karo. Dari grafik tersebut terlihat bahwa persentase tertinggi yaitu tanaman yang digunakan oleh ketiga etnis $(4,17 \%)$ dengan persentase kumulative diatas $50 \%$. 


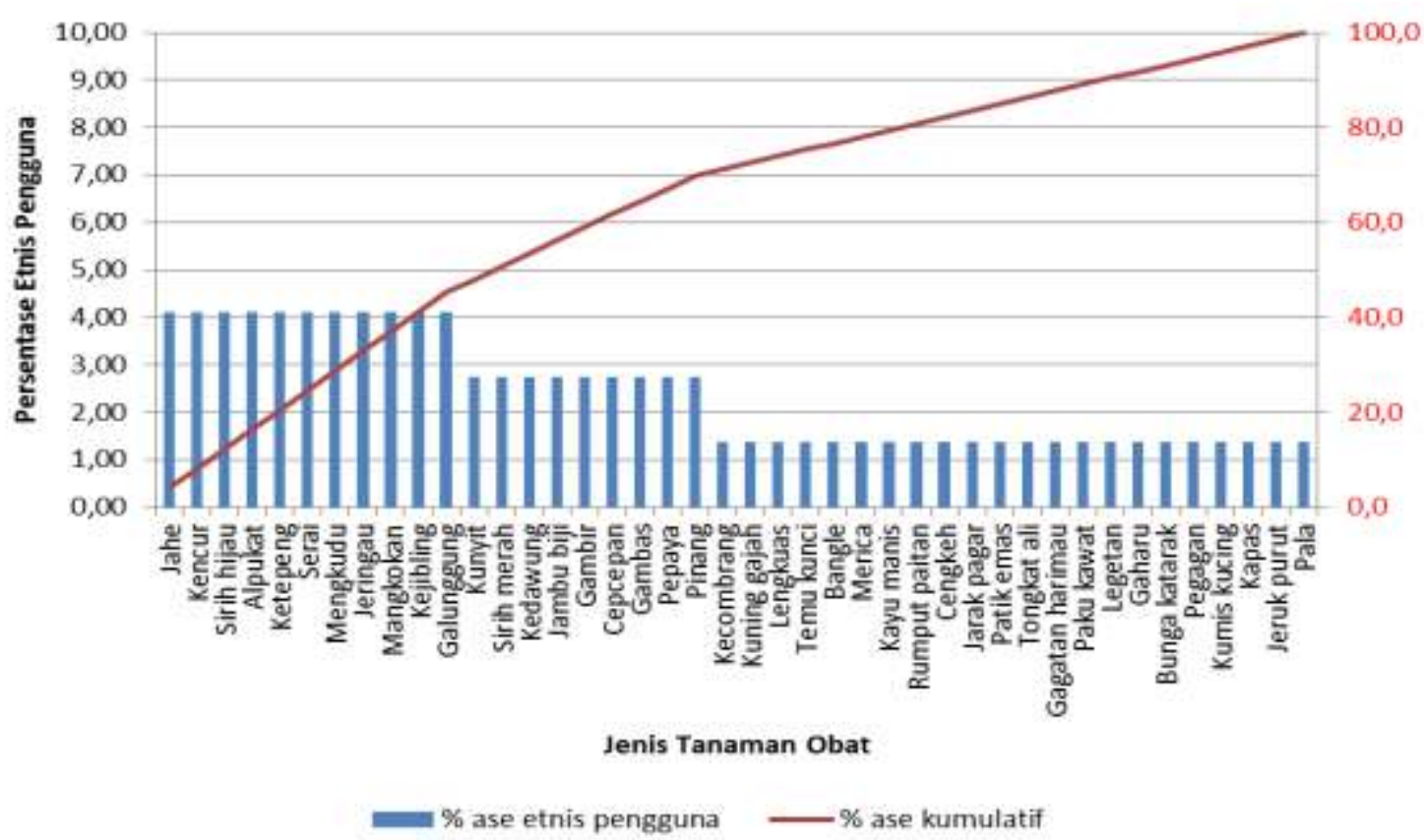

Gambar 3. Persentase jenis tumbuhan obat berdasarkan etnis yang memanfaatkan

\section{Khasiat Tumbuhan Obat}

Berdasarkan hasil penelitian, khasiat tumbuhan obat di kelompokkan menjadi 4 kelompok yaitu pengobatan, kesehatan, perawatan, dan kecantikan. Jumlah khasiat tumbuhan obat dapat dilihat pada gambar 4. Skor tertinggi dari khasiat tumbuhan obat adalah pengobatan $(60,00 \%)$ dengan 27 penyakit.

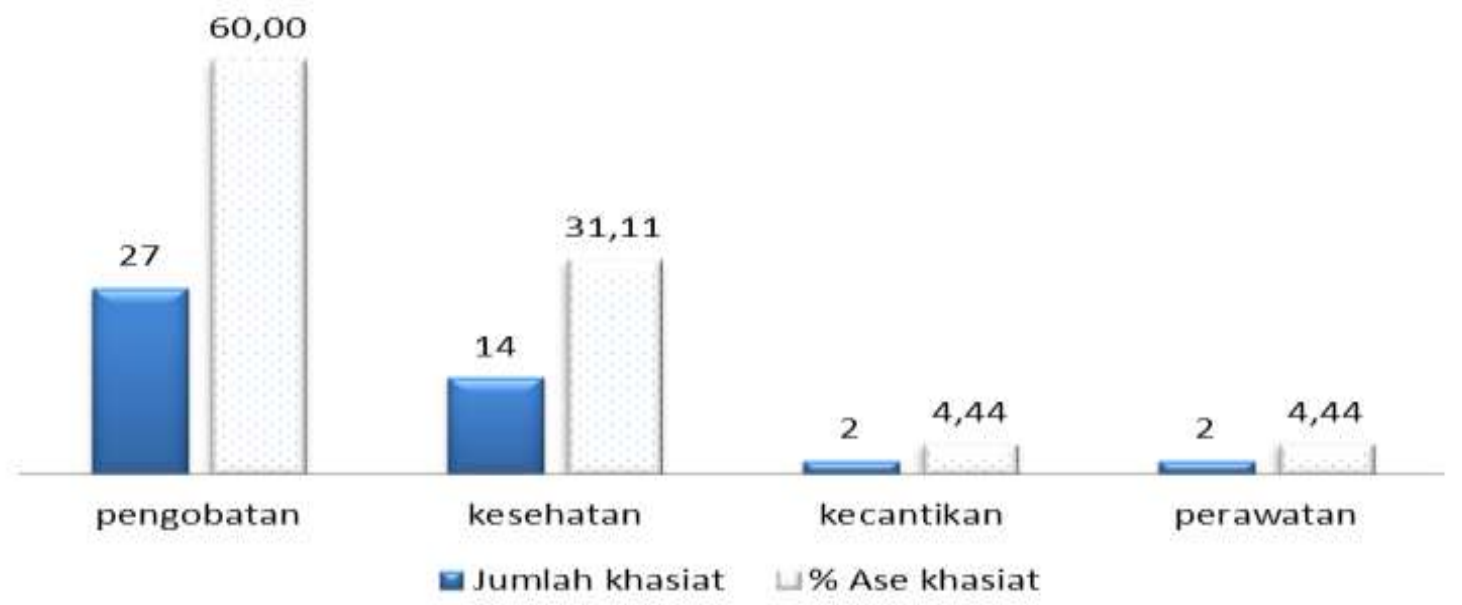

Gambar 4. Jumlah khasiat tumbuhan obat

Khasiat pengobatan yaitu untuk mengobati penyakit seperti batuk, masuk angin, diare, flu, sakit mata, sakit kuning, sakit pinggang, sakit ginjal, sakit gigi, sakit kulit, tetanus, demam, sakit kepala, pegal, demam kejang, magh, sakit tenggorokan, diabetes, liur berlebihan pada bayi, malaria, sariawan, panas dalam, obat luka, perut kembung, keputihan, patah tulang, dan sawan bayi. Skor yang kedua dari khasiat tumbuhan obat adalah untuk kesehatan tubuh
(31,11\%) dengan 14 khasiat yaitu minuman ibu melahirkan, menghangatkan badan, sebagai minyak urut, menambah nafsu makan, penambah darah, perawatan pusar bayi, penghilang rasa lelah, penangkal sawan bayi, pelancar ASI, peluruh darah kotor, obat kuat, melancarkan buang air besar, menghilangkan darah kotor, dan menurunkan tekanan darah. Skor yang ketiga yaitu kecantikan $(4,44 \%)$ dengan 2 khasiat yaitu untuk mengobati jerawat dan menghilangkan bau badan, dan 
perawatan (4,44\%) dengan 2 khasiat yaitu perawatan vagina dan perawatan setelah melahirkan. Persentase jenis tanaman obat berdasarkankhasiatnya dapat dilihat pada gambar 5 dibawah ini.

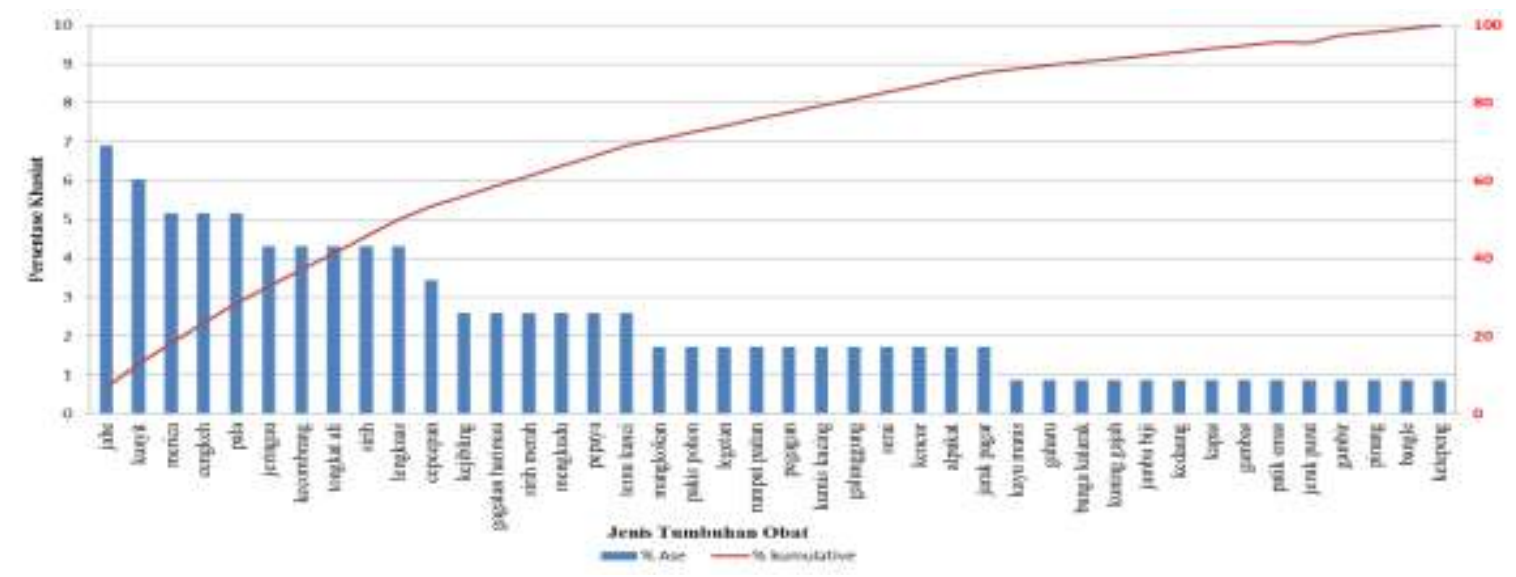

Gambar 5. Jenis tumbuhan obat berdasarkan khasiat

Pada gambar 5, terlihat bahwa tumbuhan yang paling banyak memiliki khasiat adalah jahe yang memiliki 9 khasiat dengan persentase khasiat sebesar 6,84\%. Kunyit dengan 7 khasiat (5,98\%), jeringau, merica, cengkeh, dan pala dengan 6 khasiat $(5,13 \%)$, dan kecombrang, tongkat ali, sirih, dan lengkuas yang memiliki 5 khasiat (4,27\%). 32 jenis tumbuhan obat lainnya memiliki khasiat yang rendah karena memiliki persentase kumulative dibawah 50\%. Dengan membudidayakan 10 jenis tumbuhan obat yang memiliki persentase kumulative diatas 50\%, sudah dapat memenuhi lebih dari setengah kebutuhan masyarakat untuk mengobati penyakit yang sering diderita oleh masyarakat Dusun Aras Napal Kiri dan Dusun Aras Napal Kanan Desa Bukit Mas Kecamatan Besitang.

\section{Kesimpulan \\ Simpulan}

Berdasarkan hasil penelitian yang diperoleh dapat disimpulkan bahwa terdapat 42 jenis tumbuhan dari 27 famili yang bermanfaat sebagai obat di di Dusun Aras Napal Kiri dan Dusun Aras Napal Kanan Desa Bukit Mas Kabupaten. Tumbuhan yang dimanfaatkan bagian daunnya ada 22 jenis (47,83\%), bagian rimpang ada 8 jenis $(17,39 \%)$, bagian buah dan getah masing-masing 4 jenis $(8,70 \%)$, bagian biji ada 3 jenis $(6,52 \%)$, bagian batang dan akar masing-masing 2 jenis $(4,35 \%)$, dan bagian bunga hanya 1 jenis tumbuhan $(2,17 \%)$. Etnis yang paling banyak memanfaatkan tumbuhan obat adalah Etnis jawa yang memanfaatkan 34 jenis tumbuhan obat, Etnis Karo memanfaatkan 20 jenis tumbuhan obat, dan Etnis batak memanfaatkan 19 jenis tumbuhan obat.
Khasiat tumbuhan obat di kelompokkan menjadi 4 kelompok yaitu pengobatan $(61,90 \%)$, kesehatan $(30,95 \%)$, kecantikan $(4,70 \%)$, dan perawatan $(2,38 \%)$.

Saran

Saran dari penelitian ini adalah pelu peningkatan upaya budidaya tanaman obat oleh masyarakat dan perlu dilakukan analisis lebih lanjut tentang komposisi kandungan kimia tumbuhan obat di Dusun Aras Napal Kiri dan Dusun Aras Napal Kanan Desa Bukit Mas Kecamatan Besitang.

\section{Daftar Pustaka}

Anonim. 2014. Aras Napal : Menjelajahi Keindahan Bentang Alam Ekosistem Leuser Terrestrial Plant Ecology. Diakses dari www.travelesia.co/2014/09/aras-napal.html.

A.N.S, Thomas. 2012. Tanaman Obat Tradisional. Penerbit anisius. Yogyakarta.

Dewoto, Hedi R. 2007. Pengembangan Obat Tradisional Indonesia Menjadi Fitofarmaka.Majalah Kedokteran Indonesia, Volume 57, nomor 7.

Fahreza, Irsyad. 2004. Meseum Etnobotani Indonesia di Bogor.Fakultas Tehnik Universitas Diponegoro.Semarang.

Hamzari. 2008. Ientifikasi Tanaman Obat-obatan yang dimanfaatkan oleh masyarakat Sekitar Hutan Tabo-tabo.Jurnal Ilmiah staf dosen Manajemen Hutan Universitas Tadulako.

Kandowangko, Novri, Solang, Margaretha, dan Ahmad, Jusna. 2011. Kajian Etnobotani 
Tanaman Obat Oleh Masyarakat Kabupaten Bonebolango Provinsi Gorontalo. Laporan penelitian pengembangan program studi Jurusan Biologi Fakultas MIPA Universitas Negeri Gorontalo.

Katno. 2008. Tingkat Manfaat, Keamanan, dan Efektifitas Tanaman Obat dan Obat Tradisional. Diterbitkan oleh Balai Besar Penelitian dan Pengembangan. Jawa Tengah.

Keputusan Mentri Kesehatan Republik Indonesia Nomor 1076/MENKES/SK/VII/2003 tentang penyelenggaraan pengobatan tradisional.

Mirza, Zailani. 2010. Inventarisasi Pemanfaatan Tumbuhan Obat Secara Tradisional Oleh Suku Osing Banyuwangi.Skripsi.Fakultas Keguruan dan Ilmu Pendidikan Universitas Jember.

Pratiwi, Farah Meita dan Sutara, Pande Ketut. 2013. Etnobotani Kelapa (Cocos nucifera L.) di Wilayah Denpasar. Jurnal Simbiosis Universitas Udayana. Bali.

Rozak, Abdur. 2011. Studi Etnobotani Tumbuhan yang Berpotensi Sebagai Obat Penyakit Dalam di Kecamatan Guluk-guluk Kabupaten Sumenep Madura. Skripsi. Universitas Islam Negeri Maulana Malik Ibrahim.

Sari, Lusia Oktora Ruma Kumala. 2006. Pemanfaatan Obat Tradisional Dengan Pertimbangan Manfaat dan Keamanannya. Artikel Majalah Ilmu Kefarmasian Volume III Nomor 1, 01-07

Suryadharma, IGP. 2008. Etnobotani. Diktat Kuliah Universitas Negeri Yogyakarta. Yogyakarta

Thoha, A. S. 2009. Kondisi Umum Aras Napaldan Pulau Sembilan. Lokasi Umum Praktik. Diakses dari 